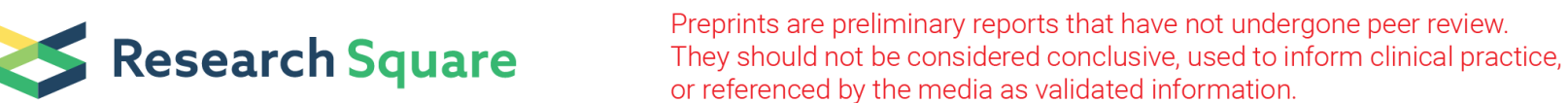

\section{An interaction effect analysis of thermodilution- guided hemodynamic optimization, patient condition, and mortality among successful cardiopulmonary resuscitation patients}

Enikő̃ Kovács ( $\square$ kovacs.eniko2@med.semmelweis-univ.hu )

Semmelweis University https://orcid.org/0000-0003-2012-1136

\section{Anna Gyarmathy}

John Hopkins University, Baltimore

Dávid Pilecky

Klinikum Passau

Alexandra Fekete-Győr

St. George`s Hospitals NHS Foundation Trust

\section{Zsófia Szakál-Tóth}

Heart and Vascular Center, Semmelweis University

\section{László Gellér}

Heart and Vascular Center, Semmelweis University

\section{Balázs Hauser}

Department of Anaesthesiology and Intensive Therapy, Semmelweis University

\section{János Gál}

Department of Anaesthesiology and Intensive Therapy, Semmelweis University

\section{Béla Merkely}

Heart and Vascular Center, Semmelweis University

\section{Endre Zima}

Heart and Vascular Center, Semmelweis University

Original research

Keywords: resuscitation, hypothermia, hemodynamic monitoring, thermodilution, mortality

Posted Date: May 28th, 2020

DOl: https://doi.org/10.21203/rs.3.rs-30868/v1

License: (c) (i) This work is licensed under a Creative Commons Attribution 4.0 International License. Read Full License 
Page $2 / 23$ 


\section{Abstract \\ Background}

Post-cardiac arrest syndrome and target temperature management have an influence on hemodynamics in a complex way. Proper hemodynamic monitoring is necessary among post-cardiac arrest patients. The aim of our study was to investigate the effects of $\mathrm{PiCCO}^{\mathrm{TM}}$-guided hemodynamic management on shortand long-term mortality in post-resuscitation therapy and to disentangle the relationship between $\mathrm{PiCCO}^{\mathrm{T}}$-application, the patients' condition, and mortality by assessing it as an interaction effect.

\section{Methods}

In this longitudinal analysis of 63 comatose patients after successful cardiopulmonary resuscitation cooled to $32-34^{\circ} \mathrm{C}, 30$ patients received no $\mathrm{PiCCO}^{\mathrm{Tm}}$ monitor application and 33 received $\mathrm{PiCCO}^{\mathrm{Tm}}$. Primary and secondary outcomes were 30-day and one-year mortality. Kaplan-Meyer curves and corresponding Log-rank tests were used to assess differences in mortality among $\mathrm{PiCCO}^{\text {TM }}$ vs non-PiCCO ${ }^{\text {TM }}$ patients. Interaction effects (patient's condition vs. $\mathrm{PiCCO}^{\text {TM }}$ application vs. mortality) were assessed by means of Chi-square tests and logistic regression models.

\section{Results}

30-day mortality was significantly, and one-year mortality was marginally higher among PiCCO ${ }^{\mathrm{TM}}$ patients. We found five interaction patterns between patients' condition and being monitored with $\mathrm{PiCCO}^{\mathrm{TM}}$ with regard to mortality after 30 days, which distilled down to three interaction patterns by the end of the first year. More severe patient condition per se was not the cause of higher mortality rate in the $\mathrm{PiCCO}^{\mathrm{Tm}}$ group. Moreover, patients in better health conditions (without ST-elevation myocardial infarction, without cardiogenic shock, without intra-aortic balloon pump device or without stroke in prior history) had worse outcomes in $\mathrm{PiCCO}^{\text {tw }}$-guided therapy. Furthermore, catecholamine administration worsened both 30-day and one-year mortality among all patients.

\section{Conclusions}

Our analysis showed that there was a complex interaction relationship between $\mathrm{PiCCO}^{\mathrm{T}}$-guided therapy, patients' condition, and 30-day mortality for most conditions. Furthermore, in terms of one-year mortality, there was either no benefit whatsoever of $\mathrm{PiCCO}^{\mathrm{TM}}$ monitoring on survival or there was worse survival among patients who had no underlying conditions but received $\mathrm{PiCCO}^{\text {TM }}$ (such as among patients who had no STEMI or had no stroke).

\section{Introduction}


Physicians face several challenges during post-cardiac arrest therapy at the intensive care unit (ICU). Post-cardiac arrest syndrome occurring after the return of spontaneous circulation (ROSC) contains reperfusion-ischemic injury, post-cardiac arrest brain injury, post-cardiac arrest myocardial dysfunction and the precipitating pathology itself that caused cardiac arrest. ${ }^{1}$ The prevention and treatment of secondary brain damage and hemodynamic management are co-dependent and both elements play an important role in post-cardiac arrest therapy. ${ }^{2}$ On the one hand, target temperature management (TTM) with target temperature of $32-36^{\circ} \mathrm{C}$ is applied as a neuroprotective tool in comatose patients surviving cardiac arrest. $^{3-5}$ On the other hand, TTM may influence circulatory system in a negative manner leading to bradycardia, arrhytmias, increased systemic vascular resistance and hypovolaemia. ${ }^{6,7}$ Post-cardiac arrest syndrome has also a plenty of factors affecting the hemodynamics harmfully. ${ }^{1}$ Moreover, a proper hemodynamic management is crucial to keep a satisfactory cerebral perfusion to prevent further cerebral deterioration. ${ }^{8}$ Therefore, advanced hemodynamic monitoring may be useful in post-resuscitation therapy. However, there is no evidence which hemodynamic parameters should be monitored and which monitoring method should be used.

The PiCCO ${ }^{\text {TM }}$ (Pulse index Contour Cardiac Output) monitoring system (Pulsion Medical Systems, Munich, Germany) guided therapy uses transpulmonary thermodilution and pulse contour analysis to determine hemodynamic parameters. ${ }^{9}$ A cold liquid bolus is applied via a central venous catheter passing through various thoracic compartments, and a peripheral arterial thermodilution catheter (mostly inserted into femoral artery) detects the temperature curve, calculating cardiac output with the modified StewardHamilton equation. ${ }^{10}$ In addition, a continuous cardiac output monitoring by recording the pulse pressure wave can also be used in $\mathrm{PiCCO}^{\mathrm{T}}$. Calculated hemodynamic parameters give further information about the circulatory system: the global end diastolic index (GEDI) reflects preload and systemic vascular resistance index (SVRI) represents afterload, while the extravascular lung water index (ELWI) gives information about pulmonary edema, and global ejection fraction (GEF) reflects cardiac systolic function.

$\mathrm{PiCCO}^{\mathrm{TM}}$ was shown to provide better monitoring capacities in critically ill patients with necrotising pancreatitis, ${ }^{11}$ sepsis ${ }^{12}$ and in cardiac surgery. ${ }^{13}$ It was also assessed during post-cardiac arrest therapy and therapeutic hypothermia $\left(32-34^{\circ} \mathrm{C}\right)$ showing that thermodilution measurements are precise in patients following ROSC, even if lower temperature is used. ${ }^{14}$ In addition, a set of triplicate injections was recommended to be applied in order to achieve the best precision. ${ }^{14}$ As such, the European Society of Intensive Care Medicine recommends the use of cardiac output monitoring (and transpulmonary thermodilution) in patients with severe shock not responding to initial treatment. ${ }^{15}$ However, to our knowledge there is no assessment regarding whether $\mathrm{PiCCO}^{\mathrm{TM}}$ monitoring guided therapy actually improves mortality outcome during post-resuscitation therapy.

Therefore, the aim of our study was to investigate the effects of $\mathrm{PiCCO}^{\text {TM}}$-guided hemodynamic management on 30-day and one-year mortality in comatose patients treated with TTM after ROSC. More specifically, we focused on disentangling the relationship between $\mathrm{PiCCO}^{\mathrm{T}}$-application, the patients' condition, and mortality by assessing it as interaction effects. 


\section{Methods}

\section{Study design}

This was a retrospective longitudinal chart review study of patients $(N=254)$ who successfully underwent cardiopulmonary resuscitation after either OHCA (out-of-hospital cardiac arrest) or IHCA (inhospital cardiac arrest) at Semmelweis University Heart and Vascular Center between January 2008 and January 2015. Institutional medical records and charts were reviewed to estimate the in-hospital management in the first 72 hours after admission. Information related to pre-hospital emergency care by OHCA patients was obtained from the records of emergency medical service and Utstein reports.

The Semmelweis University Regional and Institutional Committee of Science and Research Ethics approved our study (approval number: 19/2019). The written informed consent requirement was waived due to the retrospective nature of the study.

\section{Patients}

We included in our analysis those comatose patients who were cooled to $32-34{ }^{\circ} \mathrm{C}$ for 24 hours after ROSC on the basis of the even actual ERC (European Resuscitation Council) guidelines, ${ }^{16}$ were older than 18 years, had no end stage illness in history, were not pregnant, had no active bleeding, whose cause of cardiac arrest had a probable cardiac origin, and were not involved in a clinical trial. In addition, only patients cooled with Blanketrol IIIT (Cincinatti SubZero Products, Cincinatti, USA) thermo-feedback device were enrolled into the study - those patients whose temperature management was applied with ice packs and/or physical cooling were excluded, because target temperatures could not be reached in most of these cases. 23 patients were excluded from the study due to lack of data. After the sampling process depicted in Fig. 1, the final study sample included 63 patients (33 who were applied and 30 who were not applied $\mathrm{PiCCO}^{\text {TM }}$ monitoring).

\section{Initial therapy}

Post-resuscitation therapy and TTM were initiated as soon as possible after the admission of OHCApatients and after ROSC of IHCA-patients. All patients received standardized critical care according to our institutional protocol. An acute coronarography and percutanous coronary intervention (PCl) were performed and intra-aortic balloon pump (IABP) was inserted, if indicated. All patients were treated in the ICU at the acute phase of the assessment. We upheld mechanical ventilation until the patients fulfilled extubation criteria.

Oxygen saturation, electrocardiogram, invasive arterial blood pressure, central venous pressure, diuresis, blood gas parameters and serum lactate level were monitored for all patients. An echocardiography was performed after the admission to the ICU to assess the heart function. If it was available, the hemodynamic monitoring was augmented with $\mathrm{PiCCO}^{\text {TM }}$ monitor (Pulsion Medical System, Munich, Germany); thermodilution measurements were applied at least every 12 hours during the first 48 hours 
after the initiation of cooling. We measured the following variables: cardiac index $\left(\mathrm{Cl}: 1 / \mathrm{min} / \mathrm{m}^{2}\right)$, systemic vascular resistance index (SVRI: dyn.sec. $\mathrm{cm}^{-5}$ ), global end-diastolic volume index (GEDI: I/ $\mathrm{m}^{2}$ ), extravascular lung water index (ELWI: $\mathrm{ml} / \mathrm{kg} / \mathrm{m}^{2}$ ) and global ejection fraction (GEF: \%). If patients had IABP their device was paused for the time of thermodilution measurement.

Fluid, vasopressor, and inotrope therapy were accomplished by monitoring heart rate (HR), mean arterial pressure (MAP), central venous pressure, diuresis and lactate levels for patients without PiCCO ${ }^{\mathrm{Tm}}$. We used the goal parameters given by the actual ERC guidelines. ${ }^{16}$ The hemodynamic management was guided by $\mathrm{PiCCO}^{\mathrm{TM}}$ parameters and the decision tree of Pulsion Medical System ${ }^{17}$ was applied for $\mathrm{PiCCO}^{\mathrm{TM}}$ patients.

Noradrenaline, dobutamine, dopamine and/or adrenaline were used as vasopressors and positive inotropic agents in mono- or combination therapy. If the cardiac function was critically impaired, a 24hour long levosimendan treatment was implemented. The measured hemodynamic parameters determined which drug was chosen during the assessment based on the above mentioned therapy decision tree of Pulsion Medical System. ${ }^{17}$

TTM was divided into three phases: induction of cooling, maintenance phase, and rewarming. During the induction of TTM $30 \mathrm{ml} / \mathrm{kg}$ crystalloids were given to the patients, and the previously mentioned thermofeedback device was used. The temperature in maintenance phase was upheld with the same device. After 24 hours of hypothermia, rewarming was achieved by passively trying to keep a $0.25^{\circ} \mathrm{C} /$ hour rewarming speed until normothermia was reached. Prevention and control of fever still played an important role in the first 72 hours of the assessment. Patients received a combination of intravenous benzodiazepine and opioid as sedation during hypothermia. Their core temperature was measured with an esophageal thermometer.

Additionally, patient data extracted included the patients' age, gender, previous health conditions affecting cardiovascular system (diabetes, hypertension, stroke, hyperlipidemia, and acute myocardial infarction), circumstances of cardiopulmonary resuscitation (time between collapse and ROSC, if the patient was on monitor at the time of collapse, if basic life support was performed, and initial rhythm) and important steps of therapy after ROSC (presence of cardiogenic shock (CS), ST segment elevation and non-ST segment elevation myocardial infarction (STEMI and NSTEMI), frequency of acute PCl, frequency of IABP insertion, ejection fraction after ROSC, and necessity of levosimendan administration after ROSC).

Primary outcome was defined as mortality after 30 days and secondary outcome was defined as mortality after one year.

Patients ' changes in temperature during TTM, hemodynamic parameters, changes in serum lactate levels during TTM, and catecholamine dosing can be found in Supplement 1.

\section{Statistical analysis}


First, three sets of bivariate statistical tests were performed: we assessed differences between 1. the PiCCO and non-PiCCO groups (yes vs. no), 2. mortality after 30 days (yes vs. no) and 3 . mortality after one year (yes vs. no). Mann-Whitney's $U$ tests was used for continuous variables and Chi-square test or (in case of small sample sizes) Fisher's exact test was applied for categorical variables. Additionally, Kaplan-Meyer curves and Log-rank tests for significance were used as longitudinal data to asses differences in mortality between PiCCO and non-PiCCO groups and for those variables where mortality was at least marginally significant using the categorical Chi-square analysis. Second, interaction effects were explored (candidate variable vs. $\mathrm{PiCCO}^{\mathrm{TM}}$ use vs. mortality) using the same statistical methods as in the bivariate analysis for those variables that had at least marginal associations with both $\mathrm{PiCCO}^{\mathrm{TM}}$ use and mortality. Additionally, logistic regression analysis was performed using the interaction terms as dummy variables. If there were zero cell sizes, then dummy categories were combined with non-zero cells. In a first set of logistic regression models, all interaction dummy variables were included, and in a second set of models only statistically significant dummies stayed.

Continuous variables are described with median values and their corresponding interquartile range, and categorical data are described as percentages. Not more than $10 \%$ of the data were missing; we performed multiple imputation using the k-nearest neighbor algorithm to replace variables with missing values.

We identified $p<0.05$ for statistical significance and $p<0.2$ and $p \geq 0.05$ for marginal significance. Data management and statistical analysis was performed using TIBCO STATISTICA v13.4 (Tibco Software Inc., Palo Alto, CA), and figures were created using GraphPad Prism version 5.0 (GraphPad Software, La Jolla, CA).

\section{Results}

\section{Characteristics of patients, $\mathrm{PiCCO}^{\mathrm{mm}}$ use and 30-day and 1- year mortality}

Patient characteristics are shown in Table 1 . Altogether, $52 \%$ received $\mathrm{PiCCO}^{\mathrm{TM}}, 38 \%$ died after 30 days, and $57 \%$ died after one year. Patients with $\mathrm{PiCCO}^{\text {TM }}$ application were significantly more likely to die after 30 days, and marginally more likely to die after one year than non-PiCCO ${ }^{\mathrm{TM}}$ patients (Fig. 2). 
Table 1

Patient characteristics.

\begin{tabular}{|c|c|}
\hline & Total \\
\hline & $\mathbf{N}(\%)$ \\
\hline & or \\
\hline & Median (Quartiles) \\
\hline Total & $63(100 \%)$ \\
\hline Age & $64(56,69)$ \\
\hline Gender (female in \%) & $19(30 \%)$ \\
\hline IHCA & $11(17 \%)$ \\
\hline Past history. & \\
\hline Hypertension & $45(71 \%)$ \\
\hline Diabetes & $18(29 \%)$ \\
\hline Hyperlipidemia & $30(48 \%)$ \\
\hline AMI & $15(24 \%)$ \\
\hline Stroke & $6(10 \%)$ \\
\hline Circumstances of CPR: & \\
\hline Patient on monitor when collapsed & $9(14 \%)$ \\
\hline BLS performed by bystanders & $49(78 \%)$ \\
\hline Time to ROSC (minutes) & $20(15,30)$ \\
\hline Initial rhythm: & \\
\hline VF & $42(67 \%)$ \\
\hline VT & $2(3 \%)$ \\
\hline PEA & $10(16 \%)$ \\
\hline Asystole & $9(14 \%)$ \\
\hline Cause of cardiac arrest & \\
\hline STEMI & $38(60 \%)$ \\
\hline $\begin{array}{l}\text { AMI: acute myocardial infarction; BL } \\
\text { ejection fraction; IABP: intra-aortic b } \\
\text { patients; NSTEMI: non-ST-elevation } \\
\text { PEA: pulseless electrical activity; RO } \\
\text { myocardial infarction; VF: ventricula }\end{array}$ & $\begin{array}{l}\text { pulmonary resuscitation; EF: } \\
\text { rdiac arrest; N: number of } \\
\text { taneous coronary intervention; } \\
\text { tion; STEMl: ST-elevation } \\
\text { cardia. }\end{array}$ \\
\hline
\end{tabular}




\begin{tabular}{|c|c|}
\hline & Total \\
\hline & $\mathbf{N}(\%)$ \\
\hline & or \\
\hline & Median (Quartiles) \\
\hline NSTEMI & $8(13 \%)$ \\
\hline Cardiac condition after ROSC & \\
\hline Cardiogenic shock (clinical signs) & $14(22 \%)$ \\
\hline EF after ROSC (\%) & $36(29,48)$ \\
\hline Therapy after ROSC. & \\
\hline Catecholamine therapy & $39(62 \%)$ \\
\hline Acute PCl & $51(81 \%)$ \\
\hline Levosimendan & $7(11 \%)$ \\
\hline IABP use & $16(25 \%)$ \\
\hline Time to reach target temperature (hours) & $3,8(2.0,5.1)$ \\
\hline $\mathrm{PiCCO}^{\mathrm{TM}}$ & $33(52 \%)$ \\
\hline Died at 30 days & $24(38 \%)$ \\
\hline Died at 1 year & $36(57 \%)$ \\
\hline $\begin{array}{l}\text { AMI: acute myocardial infarction; BLS: ba } \\
\text { ejection fraction; IABP: intra-aortic balloon } \\
\text { patients; NSTEMI: non-ST-elevation myoc } \\
\text { PEA: pulseless electrical activity; ROSC: re } \\
\text { myocardial infarction; VF: ventricular fibril }\end{array}$ & $\begin{array}{l}\text { pulmonary resuscitation; EF: } \\
\text { rdiac arrest; N: number of } \\
\text { taneous coronary intervention; } \\
\text { tion; STEMl: ST-elevation } \\
\text { cardia. }\end{array}$ \\
\hline
\end{tabular}

As Fig. 3 and Supplement 2 show, at least marginal difference for both PiCCO ${ }^{\mathrm{TM}}$ application and either 30day or one-year mortality was found among patients with hyperlipidemia; prior history of stroke; STEMI as a cause of cardiac arrest; and PCI, CS, IABP, and catecholamine treatment after ROSC. Additionally, males, patients with prior history of hypertension, and those with IHCA were significantly more likely to receive $\mathrm{PiCCO}^{\mathrm{T}}$, and patients with non-shockable initial rhythm were significantly more likely to die both after 30 days and one year.

Table 1. Patient characteristics.

\section{Interaction effects between 30-day mortality, PiCCO ${ }^{\mathrm{m}}$ use and patient characteristics}


Figure 4 visualizes the multivariate interaction effects between 30-day mortality, $\mathrm{PiCCO}^{\mathrm{TM}}$ use, and patient characteristics, statistically controlled for the effects of the subgroups. Accordingly, patients with either $\mathrm{PiCCO}^{\mathrm{TM}}$ or hyperlipidemia were marginally and patients with both $\mathrm{PiCCO}^{\mathrm{TM}}$ and hyperlipidemia were significantly more likely to die at day 30 than patients with neither $\mathrm{PiCCO}^{\text {TM }}$ nor hyperlipidemia. Moreover, patients with $\mathrm{PiCCO}^{\mathrm{TM}}$ but no STEMI were significantly more likely to die than patients with no $\mathrm{PiCCO}^{\mathrm{TM}}$ or patients with both $\mathrm{PiCCO}^{\mathrm{TM}}$ and STEMI. Additionally, patients with cardiogenic shock regardless of $\mathrm{PiCCO}^{\mathrm{TM}}$ were significantly much more likely and patients with $\mathrm{PiCCO}^{\mathrm{TM}}$ but not cardiogenic shock were significantly more likely to die than patients with neither cardiogenic shock nor PiCCO ${ }^{\text {TM }}$. Furthermore, patients with $\mathrm{PiCCO}^{\mathrm{TM}}$ but no IABP were marginally and patients with IABP regardless of $\mathrm{PiCCO}^{\mathrm{TM}}$ were

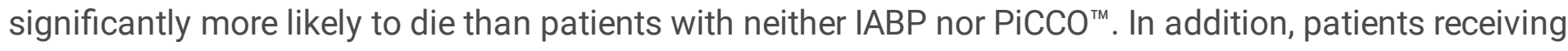
catecholamine treatment after ROSC but no $\mathrm{PiCCO}^{\mathrm{TM}}$ were marginally more likely and patients with both catecholamine and $\mathrm{PiCCO}^{\mathrm{TM}}$ were significantly more likely to die than patients with no catecholamine. Moreover, patients with no stroke but with $\mathrm{PiCCO}^{\text {тм }}$ application were significantly more likely to die than patients with neither stroke nor $\mathrm{PiCCO}^{\mathrm{TM}}$ or patients with both stroke and $\mathrm{PiCCO}^{\mathrm{TM}}$. Furthermore, higher mortality was seen in patients with $\mathrm{PCl}$ but without $\mathrm{PiCCO}^{\mathrm{TM}}$ compared to patients without $\mathrm{PCI}$ regardless of $\mathrm{PiCCO}^{\text {TM }}$ or patients with both $\mathrm{PCl}$ and $\mathrm{PiCCO}^{\text {тм }}$.

\section{Interaction effects between one-year mortality, $\mathrm{PiCCO}^{\mathrm{mm}}$ use and patient characteristics}

Multivariate interaction effects between one-year mortality, $\mathrm{PiCCO}^{\mathrm{TM}}$ use and patient characteristics, statistically controlled for the effects of the subgoups, are shown in Fig. 5. Patients with $\mathrm{PiCCO}^{\mathrm{TM}}$ but no STEMI were marginally more likely to die than patients without PiCCO ${ }^{\text {TM }}$ regardless of STEMI or patients with both $\mathrm{PiCCO}^{\mathrm{TM}}$ and STEMI. Additionally, patients recieving catecholamines after ROSC regardless of $\mathrm{PiCCO}^{\mathrm{TM}}$ were significantly more likely to die than patients who did not receive catecholamine treatment. Moreover, patients with $\mathrm{PiCCO}^{\mathrm{TM}}$ application but without stroke in past history were marginally more likely to die than patients with both stroke and $\mathrm{PiCCO}^{\mathrm{TM}}$ or patients with neither stroke and nor $\mathrm{PiCCO}^{\mathrm{TM}}$. Additionally, although no interaction was found for CS, $\mathrm{PiCCO}^{\mathrm{TM}}$ and one-year mortality, and IABP, PiCCO ${ }^{\mathrm{TM}}$ and one-year mortality, CS and IABP were independent predictors of mortality. Finally, once controlled for subgroups, the interactions between hyperlipidemia, $\mathrm{PiCCO}^{\mathrm{T}}$, and one-year mortality, and between PCl, $\mathrm{PiCCO}^{\text {тм }}$, and one-year mortality were no longer statistically significant.

\section{Discussion}

To our knowledge, there are no published studies regarding the association between PiCCO ${ }^{\mathrm{TM}}$ guided therapy and survival in post-cardiac arrest treatment. We found five interaction patterns between patients' condition and being monitored with $\mathrm{PiCCO}^{\mathrm{TM}}$ with regard to mortality after 30 days, which distilled down to three interaction patterns by the end of the first year. As such, our analysis presents a valuable insight into the nuances of advanced hemodynamic monitoring and hemodynamic management during postcardiac arrest therapy. 
The uniqueness of our study is that we disentangled the interaction effects between $\mathrm{PiCCO}^{\mathrm{TM}}$ application, mortality and patients' condition in order to elucidate the potential cause of decayed survival rate in $\mathrm{PiCCO}^{\mathrm{TM}}$ monitored patients. We found that there was a complex interaction between the use of $\mathrm{PiCCO}^{\mathrm{TM}}$ and both 30-day and 1-year mortality, depending on the condition of the patient.

We identified five groups regarding 30-day mortality. In the first group having a condition and receiving $\mathrm{PiCCO}^{\mathrm{Tm}}$ meant increased risk compared to either not having the condition or not receiving $\mathrm{PiCCO}^{\mathrm{Tm}}$, as in the case of hyperlipidemia. Specifically, 30-day mortality in patients who both had hyperlipidemia and also received $\mathrm{PiCCO}^{\mathrm{TM}}$ was higher than among those who either had no hyperlipidemia or received no $\mathrm{PiCCO}^{\mathrm{T}}$.

In the second group not having the condition but receiving $\mathrm{PiCCO}^{\mathrm{TM}}$ meant increased risk compared to either not having the condition or having the condition regardless of $\mathrm{PiCCO}^{\mathrm{T}}$, as in the case of STEMI and stroke. Specifically, 30-day mortality in patients without STEMI (without stroke, respectively) who also received $\mathrm{PiCCO}^{\mathrm{TM}}$ was higher than among those who either had no STEMI (no stroke, respectively) and received no $\mathrm{PiCCO}^{\mathrm{TM}}$, or had STEMI (stroke, respectively) regardless of $\mathrm{PiCCO}^{\mathrm{TM}}$.

In the third group having the condition or receiving $\mathrm{PiCCO}^{\mathrm{TM}}$ meant increased risk compared to not having the condition and not receiving $\mathrm{PiCCO}^{\mathrm{TM}}$, as in the case of CS and IABP. Specifically, 30-day mortality in patients who had either CS (IABP, respectively) or received $\mathrm{PiCCO}^{\text {TM }}$ was higher than among those who neither had CS (IABP, respectively) nor received PiCCO ${ }^{\mathrm{TM}}$.

In the fourth group not having the condition or receiving $\mathrm{PiCCO}^{\mathrm{TM}}$ meant increased risk compared to having the condition and not receiving $\mathrm{PiCCO}^{\mathrm{T}}$, as in the case of $\mathrm{PCl}$. Specifically, 30-day mortality in patients who had either no $\mathrm{PCl}$ or received $\mathrm{PiCCO}^{\text {TM }}$ was higher than among those who had $\mathrm{PCl}$ and did not receive $\mathrm{PiCCO}^{\text {TM }}$.

In the fifth group having the condition regardless of $\mathrm{PiCCO}^{\mathrm{Tm}}$ meant increased risk compared to not having the condition, as in the case of recieving catecholamine. Specifically, 30-day mortality in patients who received catecholamine was higher than among those who did not receive catecholamine, regardless of $\mathrm{PiCCO}^{\mathrm{T}}$.

Furthermore, we identified three groups regarding one-year mortality. In the first group, there was no difference in one-year mortality either regarding $\mathrm{PiCCO}^{\mathrm{TM}}$ application or regarding the presence of the condition, as in the case of hyperlipidemia in prior history or treatment with PCl after ROSC.

In the second group, having the condition regardless of $\mathrm{PiCCO}^{\mathrm{Tm}}$ meant increased risk compared to not having the condition, as in the case of IABP, CS and catecholamine administration. Specifically, the oneyear mortality was higher in patients treated with IABP (having CS, recieving catecholamine, respectively) than among patients without these conditions regardless of $\mathrm{PiCCO}^{\mathrm{TM}}$.

In the third group, not having the condition but receiving $\mathrm{PiCCO}^{\mathrm{TM}}$ meant increased risk compared to either not having the condition or having the condition regardless of $\mathrm{PiCCO}^{\mathrm{TM}}$, as in the case of STEMI and 
stroke. Specifically, one-year mortality in patients without STEMI (without stroke, respectively) who also received $\mathrm{PiCCO}^{\mathrm{TM}}$ was higher than among those who either had no STEMI (no stroke, respectively) and received no PiCCO ${ }^{\mathrm{TM}}$, or had STEMI (stroke, respectively) regardless of $\mathrm{PiCCO}^{\mathrm{TM}}$.

Adequate hemodynamic management is one of the key elements in post-cardiac arrest therapy. Patients after successful cardiopulmonary resuscitation may experience a global ischemic-reperfusion injury and myocardial depression, as parts of post-cardiac arrest syndrome, leading to hemodynamic instability after ROSC. ${ }^{1,18}$ Furthermore, the precipitating cause of cardiac arrest itself may result in a deterioration of hemodynamic parameters. It is also well-known that TTM has an influence on hemodynamics by several pathways. A decrease in heart rate and cardiac output, an increase in systemic vascular resistance, and hypovolaemia caused by raised diuresis may be present as consequences of lower body temperature. ${ }^{19-}$ ${ }^{21}$ As the path leading to hemodynamic instability in post-cardiac arrest syndrome is multifactorial, there is a requirement of proper monitoring tools and proper hemodynamic goal parameters to guide the therapy of these patients.

Despite the complexity of the circulatory effects in post-cardiac arrest period, there is no clear evidence and therefore guidelines about exactly which parameters should be monitored, which goal parameters should be kept during patients' management, and which monitoring tools should be used to guide the treatment. ${ }^{22-26}$ The current ERC guidelines recommend to target a mean arterial pressure to achieve a satisfactory urine output $(1 \mathrm{ml} / \mathrm{kg} / \mathrm{h})$ and a decreasing or normal serum lactate level, considering the patient's habitual blood pressure, the cause of cardiac arrest, and the severity of probable cardiac dysfunction. ${ }^{2}$ Moreover, the guidelines suggest that additional cardiac output monitoring may help to guide therapy in hemodynamically unstable patients. ${ }^{2}$ However, there is no evidence that cardiac output measuring affects outcome in this patient group.

Transpulmonary thermodilution and pulse contour analysis are applied during $\mathrm{PiCCO}^{\mathrm{TM}}$ monitoring, which allow intermittent and continuous measurements of cardiac output. Furthermore, several additional measured and calculated parameters can be estimated beside cardiac output reflecting preload, cardiac function and the vascular tone. ${ }^{9,27}$ However, artery pulmonary catheter is the gold standard of cardiac output measurement. ${ }^{28} \mathrm{PiCCO}^{\text {TM }}$ is less invasive, it is less influenced by respiratory fluctuations, and has a longer dwell time. ${ }^{29,30}$ The European Society of Intensive Care Medicine suggests the application of artery pulmonary catheter only in refractory shock with concomitant right ventricular failure. ${ }^{15} \mathrm{PiCCO}^{\mathrm{Tm}}$ was found to be effective in the evaluation of hemodynamic situations in critically ill patients, leading to a faster decision making. ${ }^{31,32}$ The PiCCO ${ }^{\mathrm{Tm}}$-guided hemodynamic management shortened the duration of vasoactive therapy, mechanical ventilation and ICU stay among elderly patients with cardiogenic shock after acute myocardial infarction. ${ }^{33}$ However, there is a lack of evidence regarding the effect of $\mathrm{PiCCO}^{\text {tm }}$ monitoring system and $\mathrm{PiCCO}^{\text {TM }}$ guided therapy on mortality in post-cardiac arrest treatment - and this is why our study findings are unique and much needed. 
The results of the interaction effect analysis between $\mathrm{PiCCO}^{\mathrm{Tm}}$ application, mortality, and patients' characteristics show that more severe patient condition per se was not the cause of higher mortality rate in the $\mathrm{PiCCO}^{\text {TM }}$ group. Moreover, patients in better health conditions (without STEMI, without cardiogenic shock, without IABP device or without stroke in prior history) had worse outcomes in PiCCO ${ }^{\mathrm{TM}}$-guided therapy. Our finding supports the literature, as the European Society of Intensive Care Medicine recommends the use of cardiac output monitoring and the application of transpulmonary thermodilution in patients with severe shock not responding to initial therapy. ${ }^{15}$

Furthermore, we need to point out that the injured brain after successful CPR frequently has an impaired autoregulation resulting the MAP dependence of cerebral blood flow. ${ }^{34,35}$ This fact raises the question if the monitoring of cardiac output and advanced hemodynamic parameters is the proper way to guide post-cardiac arrest therapy or the simpler MAP measurement and the observation of tissue perfusion give enough information.

We suggest applying $\mathrm{PiCCO}^{\mathrm{TM}}$ in post-cardiac arrest therapy in selected cases based on our results. Moreover, further prospective studies are needed to clarify which patient groups benefit from cardiac output monitoring and thermodilution methods after successful CPR.

Another important finding of our study was that catecholamine administration worsened both 30-day and one-year mortality in this patient group. It is important to clear the causality of worse survival regarding catecholamine dosage: is the catecholamine itself worsening outcome, or are the people receiving catecholamine sicker? On one hand, the side-effects of catecholamine usage (arrhythmias, increased cardiac oxygen consumption, splanchnic hyperfusion etc.) may worsen outcome and only the least necessary amount of catecholamine if any should be administered. ${ }^{36}$ On the other hand, a delay in catecholamine therapy or an improper hemodynamic stabilization may lead to tissue hypoperfusion and deterioration in patients' condition. ${ }^{37}$ Further investigation is required to explain the effects and characteristics of catecholamine treatment in post-cardiac arrest therapy.

Our study has a number of limitations, most of which are related to its retrospective nature and small sample size. Patients were enrolled into the study non-randomly, and the analysis was based on retrospectively collected data. The grouping of patients was assigned based on the availability of a $\mathrm{PiCCO}^{\text {TM }}$ monitor. However, baseline characteristics were well-balanced although due to performing only an interaction effect analysis between three variable groups but not further being able to adjust for other factors may have left some element of confounding.

The improper evaluation of $\mathrm{PiCCO}^{\mathrm{TM}}$ measurements should represent an additional limitation of our study. However, the trends of catecholamine and vasoactive dosage followed the changes of specific hemodynamic parameters, showing the adequacy of therapy. In addition, serum lactate levels decreased in parallel during and after TTM in both the $\mathrm{PiCCO}^{\mathrm{TM}}$ and non-PiCCO ${ }^{\mathrm{TM}}$ groups.

\section{Conclusion}


Post-cardiac arrest syndrome may lead to hemodynamic instability caused by multiplex factors, including the effects of TTM. Proper hemodynamic monitoring and management of hemodynamic parameters is indispensable in this patient group. The accuracy of the $\mathrm{PiCCO}^{\mathrm{Tm}}$ monitoring system was confirmed in the lower temperature environment of post-cardiac arrest therapy. However, little is known about the effectiveness of $\mathrm{PiCCO}^{\mathrm{TM}}$ regarding mortality outcomes in post-cardiac arrest patients. Our analysis showed that while there was an interaction effect between PiCCO ${ }^{\mathrm{TM}}$-guided therapy, patients condition and mortality, after 30 days for most conditions and after one year we saw either no effect of PiCCO ${ }^{\text {TM }}$ monitoring on survival or a worsening of survival among patients who had no underlying conditions and received $\mathrm{PiCCO}^{\mathrm{Tm}}$. Given the exploratory nature of our study, further investigations are needed to clarify which patients benefit from $\mathrm{PiCCO}^{\mathrm{TM}}$ monitoring during post-cardiac arrest therapy.

\section{Abbreviations}

\section{AMI}

acute myocardial infarction

BLS

basic life support

$\mathrm{Cl}$

cardiac index

CS

cardiogenic shock

CPR

cardiopulmonary resuscitation

$\mathrm{EF}$

ejection fraction

ELWI

extravascular lung water index

ERC

European Resuscitation Council

GEDI

global end diastolic index

GEF

global ejection fraction

HLP

hyperlipidemia

HR

heart rate

IABP

intra-aortic balloon pump

ICU 
intensive care unit

IHCA

in-hospital cardiac arrest

MAP

mean arterial pressure

OHCA

out-of-hospital cardiac arrest

PEA

pulseless elctrical activity

PiCCO

Pulse index Contour Cardiac Output

$\mathrm{PCl}$

percutaneous coronary intervention

ROSC

return of spontaneous circulation

STEMI

ST segment elevation myocardial infarction

SVRI

systemic vascular resistance index

NSTEMI

non-ST segment elevation myocardial infarction

TTM

target temperature management

VF

ventricular fibrillation

VT

ventricular tachycardia

\section{Declarations}

\section{Ethics approval and consent to participate}

The Semmelweis University Regional and Institutional Committee of Science and Research Ethics approved our study (approval number: 19/2019). The written informed consent requirement was waived due to the retrospective nature of the study.

\section{Consent for publication}

Not applicable. 
Availability of data and materials

All data generated and analysed during this study are available from the corresponding author on reasonable request.

\section{Competing interests}

The authors declare that they have no competing interests.

\section{Funding}

No external funding was applied to this study.

\section{Authors' contributions}

EK contributed in study design, acquisition, analysis, and interpretation of data and she wrote the paper. VAGy was involved in study design, data analysis, interpretation and statistics, and revised the draft. DP, AFGy and ZsSzT contributed to study design, acquisition and interpretation of data, and they were involved in drafting the manuscript. LG, BH, JG and BM were involved in study design, analysis and interpretation of data, added new insights to the topic and drafted the manuscript. EZ contributed to study design, analysis and interpretation of data, helped to discuss all the results and drafted the manuscript.

All authors read and approved the final manuscript and agreed to be personally accountable for the work.

\section{Acknowledgements}

Not Applicable.

\section{References}

1. Nolan JP, Neumar RW, Adrie C, Aibiki M, Berg RA, Böttiger BW, et al. Post-cardiac arrest syndrome: epidemiology, pathophysiology, treatment, and prognostication. A Scientific Statement from the International Liaison Committee on Resuscitation; the American Heart Association Emergency Cardiovascular Care Committee; the Council on Cardiovascular Surgery and Anesthesia; the Council on Cardiopulmonary, Perioperative, and Critical Care; the Council on Clinical Cardiology; the Council on Stroke. Resuscitation. 2008;79(3):350-79.

2. Nolan JP, Soar J, Cariou A, Cronberg T, Moulaert VRM, Deakin CD, et al. European Resuscitation Council and European Society of Intensive Care Medicine Guidelines for Post-resuscitation Care 2015 
Sect. 5 of the European Resuscitation Council Guidelines for Resuscitation 2015. Resuscitation. 2015;95:202-22.

3. Hypothermia after Cardiac Arrest Study Group. Mild therapeutic hypothermia to improve neurologic outcome after cardiac arrest. N Engl J Med. 2002;346:549-56.

4. Bernard SA, Gray TW, Buist MD, Jones BM, Silvester W, Gutteridge G, et al. Treatment of comatose survivors of out-of-hospital cardiac arrest with induced hypothermia. N Engl J Med. 2002;346:55763.

5. Nielsen N, Wetterslev J, Cronberg T, Erlinge D, Gasche $\mathrm{Y}$, Hassager $\mathrm{C}$, et al. Targeted temperature management at $33^{\circ} \mathrm{C}$ versus $36^{\circ} \mathrm{C}$ after cardiac arrest. N Engl J Med. 2013;369:2197-206.

6. Kovács E, Jenei Z, Horváth A, Gellér L, Szilágyi S, Király A, et al. Physiologic effects of hypothermia. Orv Hetil. 2011;152:171-81.

7. Delhaye C, Mahmoudi M, Waksman R. Hypothermia therapy: neurological and cardiac benefits. J Am Coll Cardiol. 2012;59:197-210.

8. Sundgreen C, Larsen FS, Herzog TM, Knudsen GM, Boesgaard S, Aldershvile J. Autoregulation of cerebral blood flow in patients resuscitated from cardiac arrest. Stroke. 2001;32:128-32.

9. Oren-Grinberg A. The PiCCO monitor. Int Anesthesiol Clin. 2010;48:57-85.

10. Werner M, Wernly B, Lichtenauer M, Franz M, Kabisch B, Muessig JM, et al. Pulse index continuous cardiac output measurements: time course analysis and association with clinical characteristics. Wien Klin Wochenschr. 2019;131:321-8.

11. Huber W, Umgelter A, Reindl W, Franzen M, Schmidt C, von Delius S, et al. Volume assessment in patients with necrotizing pancreatitis: a comparison of intrathoracic blood volume index, central venous pressure, and hematocrit, and their correlation to cardiac index and extravascular lung water index. Crit Care Med. 2008;36:2348-54.

12. Wang H, Cui N, Su L, Long Y, Wang X, Zhou X, et al. Prognostic value of extravascular lung water and its potential role in guiding fluid therapy in septic shock after initial resuscitation. $J$ Crit Care. 2016;33:106-13.

13. Goepfert MS, Reuter DA, Akyol D, Lamm P, Kilger E, Goetz AE. Goal-directed fluid management reduces vasopressor and catecholamine use in cardiac surgery patients. Intensive Care Med. 2007;33:96-103.

14. Tagami T, Kushimoto S, Tosa R, Omura M, Hagiwara J, Hirama $\mathrm{H}$, et al. The precision of PiCCO ${ }^{8}$ measurements in hypothermic post-cardiac arrest patients. Anaesthesia. 2012;67:236-43.

15. Cecconi M, De Backer D, Antonelli M, Beale R, Bakker J, Hofer C, et al. Consensus on circulatory shock and hemodynamic monitoring. Task force of the European Society of Intensive Care Medicine. Intensive Care Med. 2014;40:1795-815.

16. Nolan JP, Soar J, Zideman DA, Biarent D, Bossaert LL, Deakin C, et al. European Resuscitation Council Guidelines for Resuscitation 2010 Sect. 1. Executive summary. Resuscitation. 2010;81:1219-76. 
17. Pulsion M, System. PiCCO2 Technical Datasheet ref: MPI850305_R05. 2011.

18. Laurent I, Monchi M, Chiche JD, Joly LM, Spaulding C, Bourgeois B, et al. Reversible myocardial dysfunction in survivors of out-of-hospital cardiac arrest. 2002;40:2110-6.

19. Pellis T, Sanfilippo F, Ristagno G. The optimal hemodynamics management of post-cardiac arrest shock. Best Pract Res Clin Anaesthesiol. 2015;29:485-95.

20. Kozar M, Javorka K, Javorka M, Matasova K, Zibolen M. Changes of cardiovascular regulation during rewarming in newborns undergoing whole-body hypothermia. Neuro Endocrinol Lett. 2015;36:434-8.

21. Demirgan S, Erkalp K, Sevdi MS, Aydogmus MT, Kutbay N, Firincioglu A, et al. Cardiac condition during cooling and rewarming periods of therapeutic hypothermia after cardiopulmonary reuscitation. BMC Anesthsiol. 2014;14:78.

22. Sunde K, Pytte M, Jacobsen D, Mangschau A, Jensen LP, Smedsrud C, et al. Implementation of a standardised treatment protocol for post resuscitation care after out-of-hospital cardiac arrest. Resuscitation. 2007;73:29-39.

23. Gaieski DF, Band RA, Abella BS, Neumar RW, Fuchs BD, Kolansky DM.Early goal-directed hemodynamic optimization combined with therapeutic hypothermia in comatose survivors of out-ofhospital cardiac arrest. 2009;80:418-424.

24. Beylin ME, Perman SM, Abella BS, Leary M, Shofer FS, Grossestreuer AV, et al. Higher mean arterial pressure with or without vasoactive agents is associated with increased survival and better neurological outcomes in comatose survivors of cardiac arrest. Intensive Care Med. 2013;39:1981-8.

25. Kilgannon JH, Roberts BW, Jones AE, Mittal N, Cohen E, Mitchell J, et al. Arterial blood pressure and neurologic outcome after resuscitation from cardiac arrest. Crit Care Med. 2014;42:2083-91.

26. Walters EL, Morawski K, Dorotta I, Ramsingh D, Lumen K, Bland D, et al. Implementation of a postcardiac arrest care bundle including therapeutic hypothermia and hemodynamic optimization in comatose patients with return of spontaneous circulation after out-of-hospital cardiac arrest: a feasibility study. Shock. 2011;35:360-6.

27. Litton E, Morgan M. The PiCCO monitor: A review. Anaesth Intensive Care. 2012;40:393-409.

28. Swan HJ, Ganz W, Forrester J, Marcus H, Diamond G, Chonette D. Catheterization of the heart in man with use of a flow-direceted balloon-tipped catheter. N Engl J Med. 1970;283:447-51.

29. Gassanov N, Caglayan E, Nia A, Erdmann E, Er F. Hemodynamic monitoring in the intensive care unit: Pulmonary artery catheter versus PiCCO. Dtsch Med Wochenschr. 2011;136:376-80.

30. Gassanov N, Caglayan E, Nia A, Erdmann E. Er F.The PiCCO catheter. Dtsch Med Wochenschr. 2010;135:2311-4.

31. Monnet X, Teboul JL. Transpulmonary thermodilution: Advantages and limits. Crit Care. 2017;21:147.

32. Lichtwarck-Aschoff M, Zeravik J, Pfeiffer UJ. Intrathoracic blood volume accurately reflects circulatory volume status in critically ill patients with mechanical ventilation. Intensive Care Med. 1992;18:142-7. 
33. Zhang YB, Zhang ZZ, Li JX, Wang YH, Zhang WL, Tian XL, et al. Application of pulse index continuous cardiac output system in elderly patients with acute myocardial infarction complicated by cardiogenic shock: A prospective randomized study. World J Clin Cases. 2019;7:1291-301.

34. Sundgreen C, Larsen FS, Herzog TM, et al. Autoregulation of cerebral blood flow in patients resuscitated from cardiac arrest. Stroke. 2001;32:128-32.

35. Kilgannon JH, Roberts BW, Jones $\mathrm{AE}$, et al. Arterial blood pressure and neurologic outcome after resuscitation from cardiac arrest. Crit Care Med. 2014;42:2083-91.

36. Feneck RO, Sherry KM, Withington PS, Oduro-Dominah A, European Milrinone Multicenter Trial Group. Comparison of the hemodynamic effects of milrinone with dobutamine in patients after cardiac surgery. J Cardiothorac Vasc Anesth. 2001;15:306-15.

37. Bai X, Yu W, Ji W, Lin Z, Tan S, Duan K, et al. Early versus delayed administration of norepinephrine in patients with septic shock. Crit Care. 2014;18:532.

\section{Figures}

\section{Patients after successful cardiopulmonary resuscitation at Semmelweis University Heart and Vascular Center between January 2008 and January 2015}
Exclusion criteria ( $\mathrm{N}=154)$ :
- Not comatose after ROSC
- Did not receive hypothermia
- Age < 18 years
- End stage illness in history
- Pregnancy
- Active bleeding
- Cause of cardiac arrest was hypovolemia or sepsis
- Involved in a clinical trial

$\mathrm{PiCCO}^{\mathrm{TM}}$ group $\mathrm{N}=33$ patients

\section{4 patients}

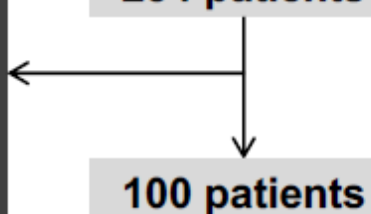

Hypothermia with thermofeedback device $(\mathrm{N}=14)$

Exclusion due to lack of data $(\mathrm{N}=23)$

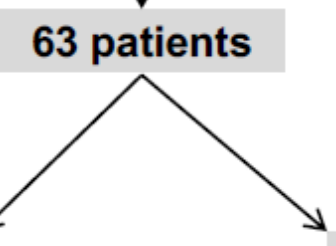

nonPiCCO ${ }^{\mathrm{TM}}$ group $\mathrm{N}=30$ patients

Figure 1 
The selection of study population and eligibility of patients. 254 patients after successful cardiopulmonary resuscitation were screened and 63 were included into the study based on the inclusion and exclusion criteria.
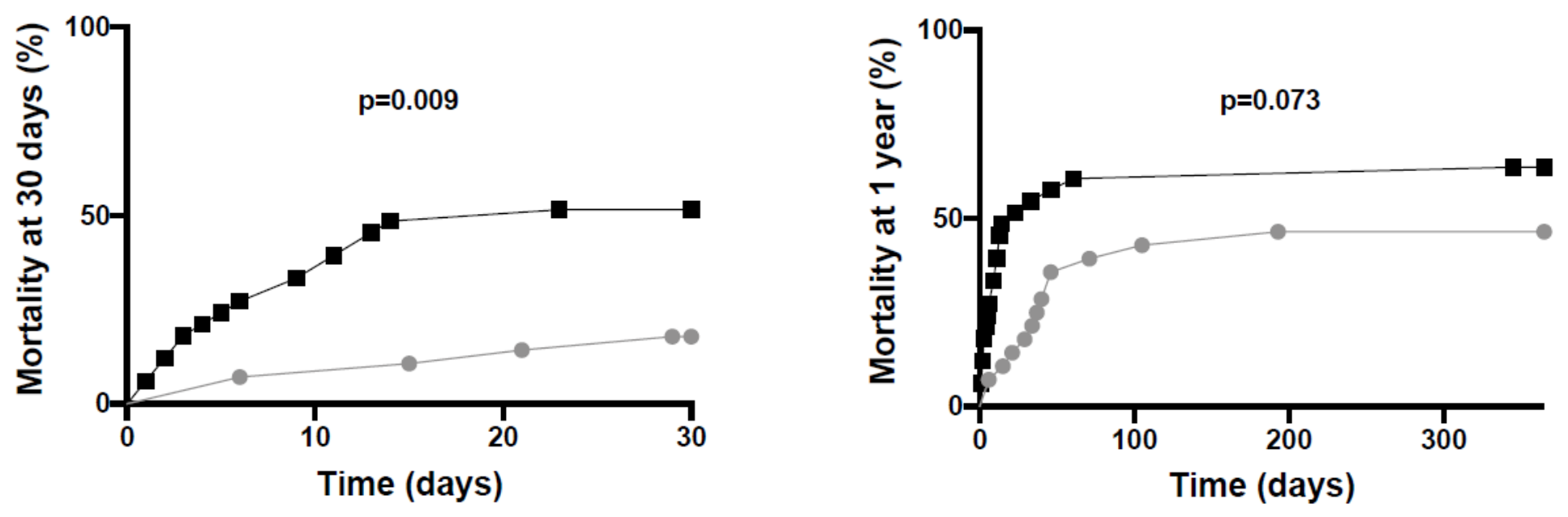

Figure 2

Cumulative incidence of 30-day and one-year mortality by PiCCO status - Log-rank test.
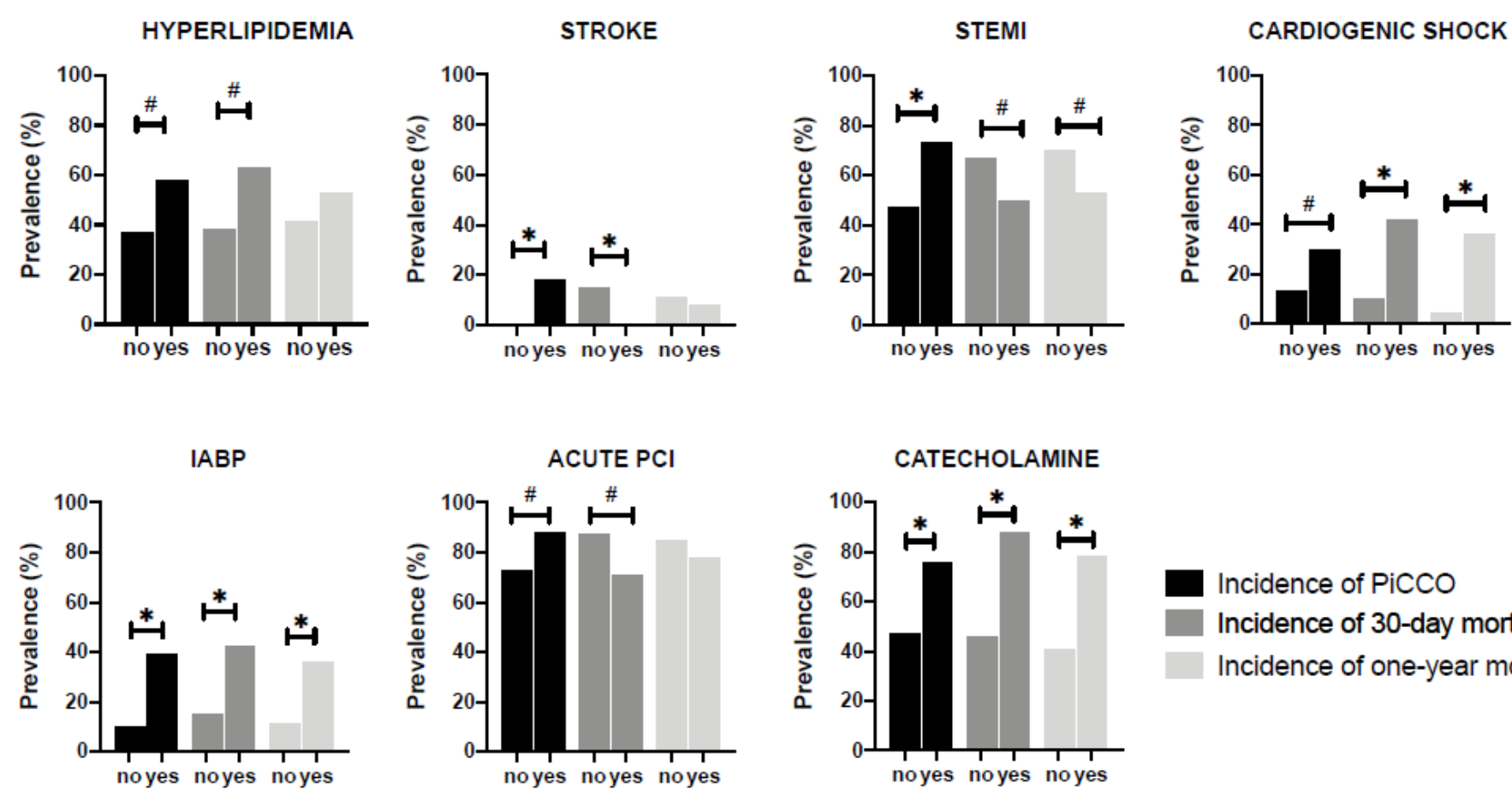

Incidence of Picco

Incidence of 30-day mortality Incidence of one-year mortality

Figure 3 
Comparison of PiCCO use, 30-day mortality, and one-year mortality by patient condition characteristics Chi-square test. Notes: $*$ : $p<0.05$; \#: $p<0.2$; STEMI: ST-elevation myocardial infarction; IABP: intra-aortic balloon pump; $\mathrm{PCl}$ : percutaneous coronary intervention.

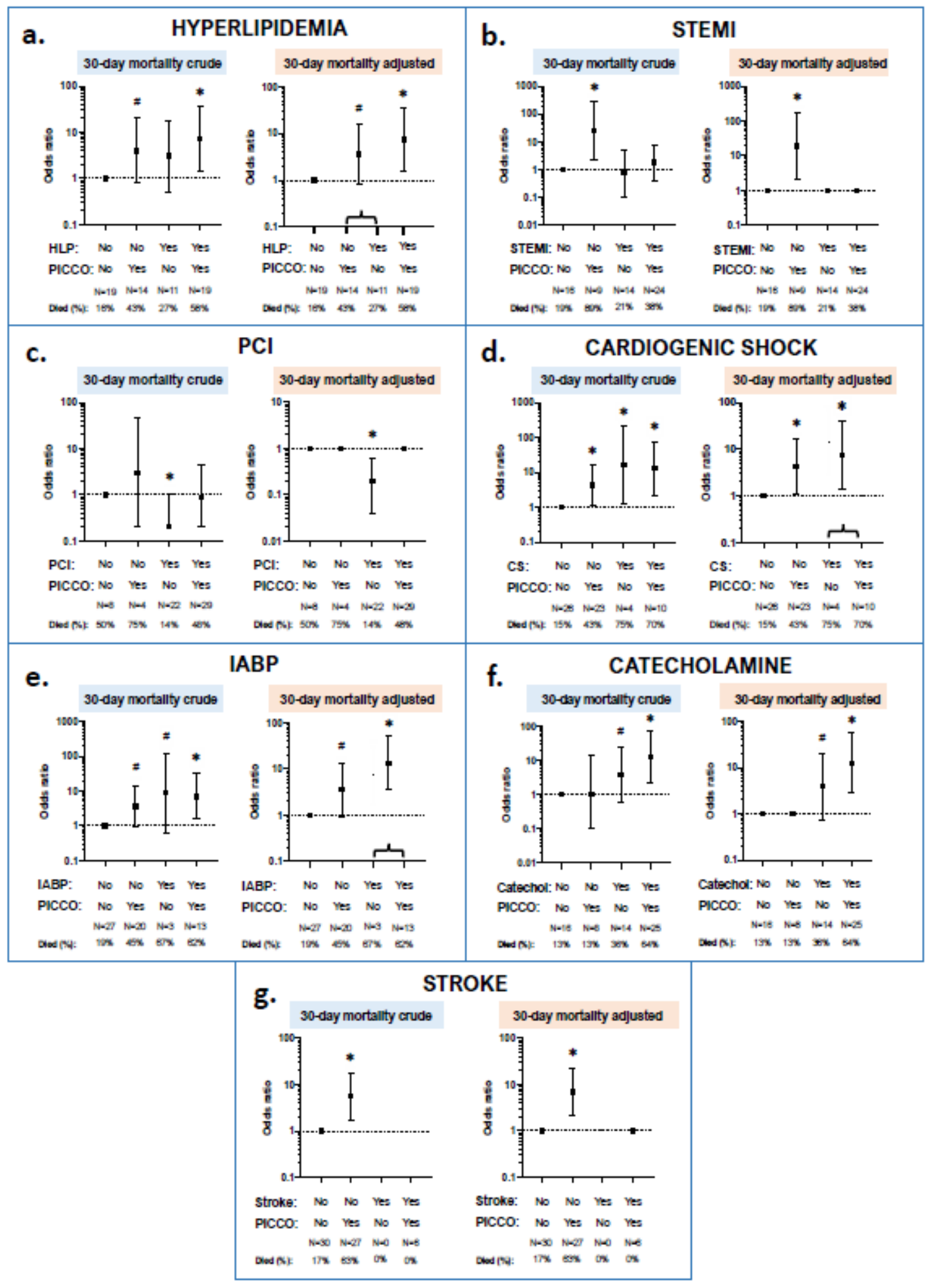

Figure 4

Interaction effects between PiCCO-application, 30-day mortality and patient condition characteristics crude and adjusted logistic regression. Notes: In the crude models, all the interaction term dummy 
variables were included as separate variables. In the adjusted models, non-significant dummies were combined. *: $p<0.05 ; \#$ : $p<0.2 ;$ HLP: hyperlipidemia; STEMI: ST-elevation myocardial infarction; PCl: percutaneous coronary intervention; CS: cardiogenic shock; IABP: intra-aortic balloon pump; catechol: catecholamine; N: number of patients.

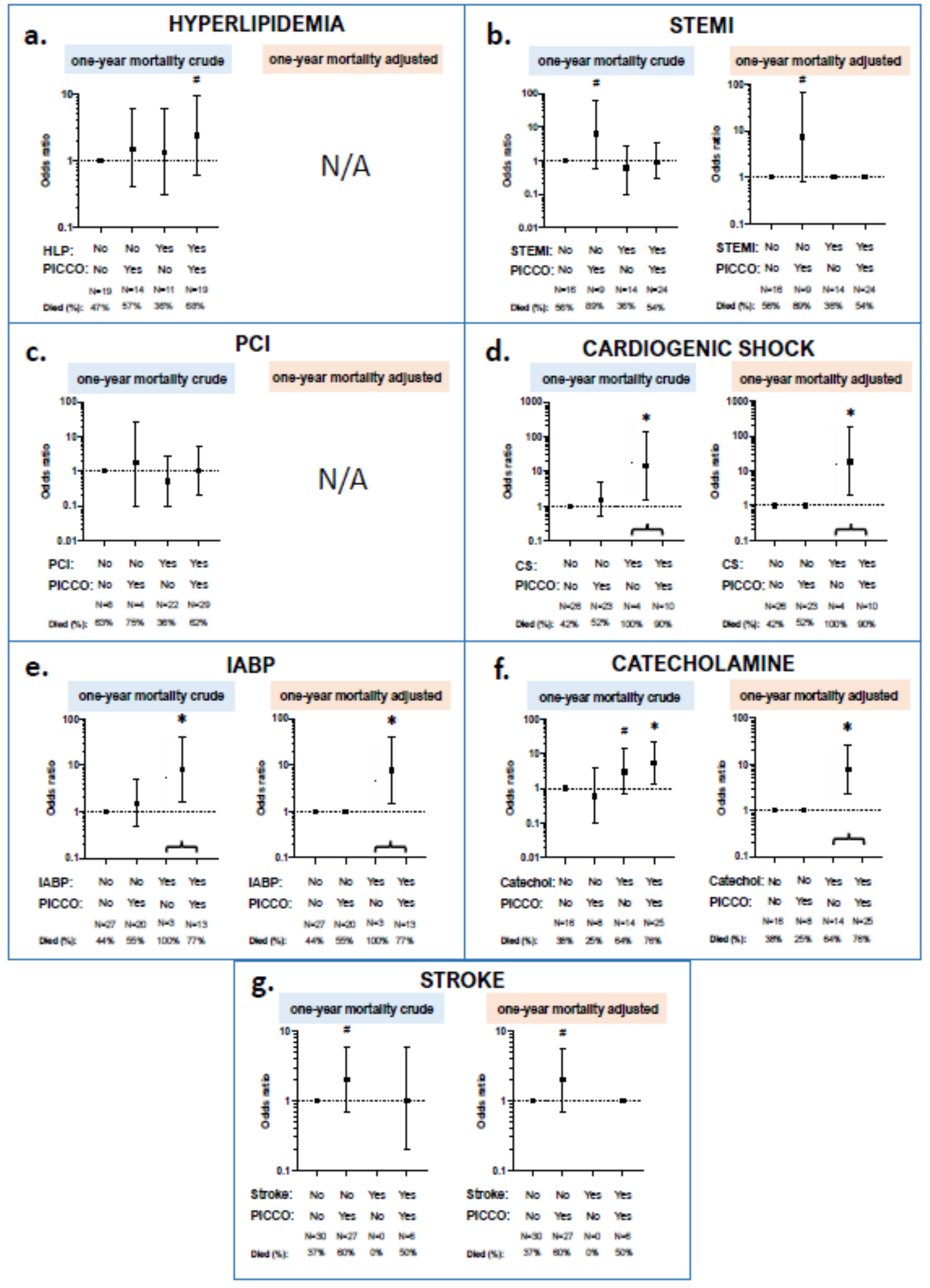

Figure 5 
Interaction effects between PiCcO-application, one-year mortality, and patient condition characteristics crude and adjusted logistic regression. Notes: In the crude models, all the interaction term dummy variables were included as separate variables. In the adjusted models, non-significant dummies were combined. $*$ : $p<0.05$; \#: $p<0.2$; HLP: hyperlipidemia; STEMI: ST-elevation myocardial infarction; PCl: percutaneous coronary intervention; CS: cardiogenic shock; IABP: intra-aortic balloon pump; catechol: catecholamine; N: number of patients.

\section{Supplementary Files}

This is a list of supplementary files associated with this preprint. Click to download.

- Supplement2.pdf

- Supplement1.pdf 